\title{
The Publication Output and Impact of various Faculties in Sri Lankan Universities: a Scientometric Assessment and Policy Implications
}

Thuraiyappah Pratheepan ${ }^{1}$ and W. A. Weerasooriya ${ }^{2}$

\begin{abstract}
This paper aims to evaluate the faculty research performance on the basis of publication output, citations and h- index of professors working in Sri Lankan universities. Six hundred fifty professors from different universities of Sri Lanka served as respondents. Using scientometrics, publications of professors spanning 1980-2014 are analyzed. It found that based on the mean h-index used in this study, faculty of science is the best performer with the mean h-index of 5.55, followed by medicine (5.24), engineering (3.81), agriculture (3.76), management (2.74) and arts (2.62). This study further revealed that, the faculty of agriculture has the highest percentage $(97.37 \%$.) of professors with published output; they have at least one research paper. Study also measured the universities' position in the each disciplines on the basis of the mean h-index. The results showed that out of six faculties, which are grouped in this study, University of Peradeniya (PDN) is found to be the most predominant in agriculture, arts, science and engineering). In medicine, University of Kelaniya is the best on the basis of the mean h-index with 6.85 . In the case of the faculty of management, University of Jaffna had the highest mean h-index of 7.75. On the other hand result indicates that the performance of arts among almost all of the universities except University of Colombo and PDN were very poor and similar. It is recommended that research output on arts, social sciences and management across the university faculty must be strengthened and mechanism should be introduced by the authorities.
\end{abstract}

Keywords: Citation analysis, h-index, Scientometrics, Bibliometrics, Sri Lankan universities, Publications.

\section{Introduction}

The universities of a country influence in all aspects of a country's future, its development and place the country in the knowledge map of the world. The

\footnotetext{
${ }^{1}$ Assistant Librarian, Uva Wellassa University of Sri Lanka. Email: pratheepan12345@gmail.com

${ }^{2}$ Professor, Department of Library and Information Science, University of Kelaniya, Sri Lanka.Email:sooria29@yahoo.com
} 
higher education system of Sri Lanka being one of the prime in South Asia, the responsibility rests on the authority to devise policies with a view to improve the quality of higher education by promoting the output of academics. There is an increasing interest in the evaluation of universities using some important aspects, particularly research and scientific activities of the departments or faculties. World universities are transforming their policy from teaching - centered to research - centered. In general, university academics engage in teaching, learning and research.

Academic scholars or researchers receive recognition, promotion and funding for future research through their publication. To cope with the modern challenges an academician should be an outstanding researcher. There are no "teaching-only" universities in Sri Lanka, as all academics are required to carry out both research and teaching. As discussed by Etzkowitz (2003) that the transformation of the university from a teaching institution into one that combined teaching with research, is still ongoing all over the globe. So, Research output can be considered as valid and useful tool in the evaluation process of university performance. The British research system, through its Research Assessment Exercise (http://www.rae.ac.uk), has achieved a highquality level of evaluation, and is probably the example to follow (Imperial and Navarro, 2007).

Measuring research output of individuals, faculty, institutions and countries has attracted much interest worldwide. Pethiyagoda (2005) noted that many senior scientists agreed in their dismay at the apparent decline in the scientific competence of Sri Lanka. This statement may not be an accepted fact now, because studies showed that Sri Lankan research output has progressed in recent years. As found by Mehbuba and Rousseau (2010) in their analysis, Sri Lanka is the best performer among the Indian subcontinent (India, Pakistan, Bangladesh and Sri Lanka). However, researchers can take Pethiyagoda's statement as a warning in the journey of Sri Lankan scientists towards a research hub.

Creating the vibrant research culture and promoting the individual researchers in order to move up in their quality and quantum of research is well understood by the administrators and policy makers of Higher Educational Institutions of 
Sri Lanka. It is true that performance of the universities/institutes can be expressed on the basis of publications generated by the faculties, and citations received by them in a particular period of time. Therefore, the university performance in the research areas is a sum of the research output, citation / hindex of the individual academics of the university. As discussed by Colliandera and Ahlgren (2011) in detail, the increasing importance has to be placed on the need for research funding entities, like universities and government offices, to assess the quality of applicants received for funding. From this standpoint the absolute need to evaluate research productivity of universities, faculty and teachers in Sri Lanka based on commonly used method is a viable and sensible task.

When faculties/universities want to revise their policy in order to keep face with the changing policy of higher education or compare research productivity against their peers, Scientometrics indicators can be a valuable tool. Scientometrics indicators have become an important tool to monitor the progress of research groups in recent decades (Fakhree and Jouyban, 2011). However, the indicators are not the most accurate ones. It is a common method used for the evaluation of the output of researchers. Wickremasinghe (2008) has argued that gaps and shortcomings could exist in evaluating research productivity of scientists through their publications.

\section{Sri Lankan Universities and Research Output}

The Higher Education Ministry of Sri Lanka officially recognizes a total of fifteen universities under the control of the University Grants Commission with authority to issue legally recognized degrees. They have a total academic staff strength of about 5000, including around 650 Professors and 2000 senior academics with PhDs or equivalent qualifications and nearly another 2,000 with other Post graduate qualifications. They are involved in academic activities in a multitude of faculties including Engineering, Medicine, Life Sciences, Agriculture, Management, Arts and Social Sciences. Out of the fifteen Universities, University of Peradeniya has the largest academic community with over 700 followed by University of Kelaniya with over 500 and University of Colombo with over 400 in next positions respectively. 
Compared to other universities of Sri Lanka Uva Wellassa University has the lowest academic community with 88 academic staff. Sri Lankan universities strive for international reputation. The reputation or /and recognition of the university mainly depends on the quality of academic research output. Research publications became necessary to seek funds from funding agencies, particularly government agencies for scientific research. Research output of university academics contribute significantly to national development, through their impact on future growth; Government supports university academics by spending millions of rupees for R\&D activities and the nation gains from the learning and innovation that occur in universities.

A few scientometric studies have been reported about Sri Lankan researchers and institutes. Gupta et al. (2002) studied India's collaboration with South Asian countries during 1992-1999 using Science Citation Index (SCI) database. Pethiyagoda (2005) critically evaluated the importance of research output and present status of Sri Lanka on the basis of a number of research papers published in the Science Citation indexed journals. Wickremasinghe (2008) studied the research productivity of rice scientists in India and Sri Lanka based on the data collected at one institute each in India and Sri Lanka using a structured questionnaire. Mehbuba and Rousseau (2010) have studied the scientific research in the Indian subcontinent using three relative indicators to compare India, Bangladesh, Pakistan and Sri Lanka.

Pratheepan (2011) has studied the research productivity of Sri Lankan universities, by using ISI WOS, which showed the contribution of the universities was about $72.46 \%$ in total research productivity during the period 1999-2010. Gupta (2012) studied the research output of Sri Lanka in S\&T during 2001-2010 on the basis of several parameters including its growth and global publications share, citation impact etc.

These studies provide us with a framework to compare research findings from any new research on the research output of Sri Lankan academics. However, to the best of authors' knowledge, there have been no prior studies that investigated the research output of professors working in different faculties of Sri Lankan universities on the basis of scientometrics indicators using Google Scholar. The objective of this study is to evaluate and measure the faculty wise 
research performance on the basis of publication output, citations and h- index of professors in Sri Lankan universities.

\section{Methods and Materials}

The method adopted in this work is completely scientometric. This study relates to the publication output and impact of 650 professors working in different faculties in Sri Lankan universities. This covers a wide range of publications spanning 1980-2014. In Sri Lanka, university academics are usually promoted to professor grade in their 40s or after two decades of academics activity in terms of their performance. Therefore, the period covered in this study is significant in the evaluation process. In this study, Professors from the each faculty have been evaluated individually on the basis of three important indicators such as research output, citation count and hindex. Study consider, number of publications by Professors as proxy of faculty output, Likewise, the total number of citations received by Professors as a proxy for faculties' quality indicator, and h-index of professor as quality \& quantity indicator in this study. Guan and Gao (2008) showed that the number of publications is one of the indicators for the assessment of scientific activities. Balaram (2008) discussed that the practice of using citation counts to quickly gauge a scientist's performance has been commonplace. $\mathrm{H}$ - index is a yardstick that is used widely for measuring the research output of individual researcher, faculty and university in terms of publications and citations received. It was proposed by Hirsch (2005) as a useful way to characterize the scientific output of a researcher. It is also increasingly seen as a convenient summary of quantity \& impact and used in many research assessments. The h-index is defined as follows: "A scientist has index $\mathrm{h}$ if $\mathrm{h}$ of his/her $\mathrm{Np}$ papers have at least $\mathrm{h}$ citations each, and the other $(\mathrm{Np}-\mathrm{h})$ papers have no more than h citations each" (Hirsch 2005).Percentage and number of professors have been mapped based on their performance under the three indicators in different range values for the 06 faculties. In addition to this, we computed the mean h-index to identify the overall performance of all faculties and universities' position in each faculty. This section also addresses the sample included in this study and data collection process. 


\section{Sample}

Professors generally constitute a group of high performing academics and researchers in the universities with excellent research records. Therefore, they are particularly suitable for this study. Sample of this study covers all professors (associate professors, professors and senior professors) who were working in the universities of Sri Lanka as on January 2015; university websites were individually accessed for listing of professors working in different faculties. If university websites were inaccurately reflected current active professors and their names, the data of this study, would be consequently inaccurate to a certain degree. The faculties grouped into six major disciplines (1.Arts \& Social Sciences - Humanities and Law included, 2.Agriculture - Veterinary science included 3.Engineering, 4.Science, 5.Medicine, 6.Management) which are widely available in the universities of Sri Lanka and based on the relevant of subjects. Total number of professors in relation to each faculty and university is listed in table 1. A total of 650 professors from the university faculties of Sri Lanka represent the 13 universities. There were no professors in two universities (South Eastern University and Uva Wellassa University).

\section{Data collection}

The data for this study were collected from the Google Scholar using Publish or Perish software (Harzing, 2007). The search strategies used in this study is similar to those applied by Harzing (2013, 2014). García-Pérez (2011) studied that sources providing complete and accurate records are necessary for evaluation of the impact of research at the individual, institutional and national level. Jacsó (2010) argued the shortcomings of Google Scholar about the level of accuracy of citation counts in Google Scholar. Based on Ilan (2008) examination and discovery of higher citation counts, he/she recommended that researchers should consult Google Scholar in addition to other commercial citation databases. Further, recent investigations of Google Scholar accuracy (Harzing, 2013) suggested that the level of accuracy, stability and comprehensiveness provided by Google Scholar is sufficient for broad-level evaluation. There is a specific problem in Google Scholar about accuracy when searching on its own interface for scientometric analysis. Therefore, Publish or Perish software is the best solution to obtain scientometric data with a wide range of citation metrics from Google Scholar. 
Today it is an accepted fact that Google Scholar is a suitable data source for scientometric research purposes than it has been in the past. This study does not include the informal publications and others that are not covered by Google scholar. It should not be forgotten that the total output and citations $/ \mathrm{h}$ index counted in this study based on the Google Scholar has to be taken as a reliable estimate of output, rather than precise values.

The prepared list of professors of each faculty were searched individually using Publish or Perish software to list out their articles, citations and h-index. (The searching of this work was done during 02-28 of February, 2015.) Searching the names of the professors with single initial was a problem because of homonyms among names. To eliminate ambiguities, maximum initials for the name of professors as available in the official websites of the universities were used as guide. False matches were verified and removed manually in three steps. 1. Cross checking the name of the author with his/her affiliation -Department, Faculty, University, Country); 2.A comprehensive review of co-authors, and publication titles; 3. A detailed verification of publications retrieved to ensure veracity of authority. Search excluded books, book chapters, working papers, reports, patents, industry-sponsored manuscripts, articles in press.

The verification and merging process was surprisingly quick when searching for professors with more than one initials. It was not applicable to professors who were published articles with a single initial. It is very common for Tamil authors/professors. It was also another problem about accuracy as observed by Choi et al. (2013), i.e. professors publishing articles under different names. However, these technical limitations have been addressed and overcome to the best of our ability, even though it is not the most accurate one. Abramo et al. (2008) developed an effective disambiguation procedure to attribute listed publications to unequivocally identified university authors. To complete the entire data collection process for a professor took about 10 minutes in most cases. However, authors of this paper required a bit more time for professors with namesakes. 
Table 1 Distribution of Profes sors working in various faculties of the Sri Lankan universities

\begin{tabular}{|c|c|c|c|c|c|c|c|}
\hline University & $\begin{array}{l}\text { Arts \& Social } \\
\text { Sciences }+\end{array}$ & Agriculture ++ & $\begin{array}{l}\text { Engineering } \\
++\end{array}$ & Science & Medicine & $*$ Management $* *$ & Total \\
\hline $\mathrm{CBO}$ & 29 & - & - & 32 & 40 & 5 & 106 \\
\hline PDN & 24 & 45 & 19 & 24 & 31 & - & 143 \\
\hline SJP & 17 & - & - & 27 & 25 & 12 & 81 \\
\hline KLN & 61 & - & - & 31 & 23 & 3 & 118 \\
\hline MRT & - & - & 56 & - & - & - & 56 \\
\hline UJA & 13 & 1 & - & 10 & 2 & 2 & 28 \\
\hline RUH & 20 & 18 & - & 12 & 12 & 1 & 63 \\
\hline OUSL & 3 & - & 7 & 6 & - & - & 16 \\
\hline EUSL & 3 & 1 & - & 1 & - & - & 5 \\
\hline SEUSL & - & - & - & - & - & - & - \\
\hline RUSL & 1 & 2 & - & - & 6 & - & 9 \\
\hline SUSL & 2 & 3 & - & 4 & - & - & 9 \\
\hline WUSL & - & 6 & - & - & - & - & 6 \\
\hline UWU & - & - & - & - & - & - & - \\
\hline VPA & 10 & - & - & - & - & - & 10 \\
\hline Total & 183 & 76 & 82 & 147 & 139 & 23 & 650 \\
\hline
\end{tabular}

$C B O$ - University of Colombo, $P D N$ - University of Peradeniya, SJP - University of Sri Jayewardenepura, $K L N$ University of Kelaniya, MRT - University of Moratuwa, UJA - University of Jaffna, RUH - University of Ruhuna, OUSL - Open University of Sri Lanka, EUSL - Eastern University, Sri Lanka, SEUSL - South Eastern University of Sri Lanka, RUSL - Rajarata University of Sri Lanka, SUSL - Sabaragamuwa University of Sri Lanka, WUSL - Wayamba University of Sri Lanka, UWU - Uva Wellassa University, UPA - University of the Visual and Performing arts.

Note. + Humanities, Arts, Law and Social Sciences included, ++ Agriculture \& Veterinary science included, ++ All Faculties of the University of Moratuwa included under Engineering, * Medicine and Dental Science are included , '** Management and Commerce are included,

\section{Results}

The performance of professors in various faculties was mapped in three tables each under one indicator such as number of publications, total citations and hindex. Simple tabulation of data with percentage in different range values was used to analyze the faculty performance.

\section{Publication -based analysis}

Table 2 presents the counts of publications published by professors of six faculties. It was observed that majority of professors from all faculties have

\begin{tabular}{lllllll}
\multicolumn{6}{l}{ Table 2 Distribution of Professors } & working in various faculties of Sri Lankan universities on the basis of publication output \\
\hline Output & Engineering & Agriculture & Medicine & Science & Management & Arts \\
Range values & No. $(\%)$ & No. $(\%)$ & No. $(\%)$ & No. $(\%)$ & No. $(\%)$ & No. $(\%)$ \\
\hline No Record\# & $11(13.41)$ & $2(2.63)$ & $8(5.76)$ & $4(2.72)$ & $2(8.69)$ & $116(63.39)$ \\
$1-50$ & $64(78.05)$ & $71(93.42)$ & $116(83.45)$ & $132(89.80)$ & $21(91.31)$ & $67(36.61)$ \\
$51-100$ & $7(8.54)$ & $2(2.63)$ & $12(8.63)$ & $9(6.12)$ & $0(0)$ & $0(0)$ \\
$101-150$ & $0(0)$ & $0(0)$ & $2(1.44)$ & $1(0.68)$ & $0(0)$ & $0(0)$ \\
$151-200$ & $0(0)$ & $1(1.32)$ & $1(0.72)$ & $0(0)$ & $0(0)$ & $0(0)$ \\
$201-250$ & $0(0)$ & $0(0)$ & $0(0)$ & $0(0)$ & $0(0)$ & $0(0)$ \\
$251-300$ & $0(0)$ & $0(0)$ & $0(0)$ & $1(0.68)$ & $0(0)$ & $0(0)$ \\
Total & $82(100 \%)$ & $76(100 \%)$ & $139(100 \%)$ & $147(100 \%)$ & $23(100 \%)$ & $183(100 \%)$ \\
\hline
\end{tabular}

Note \# Includes Professors whose results could not found and have no publication 
published research papers in the range value of 1-50 except faculty of arts. Faculty of engineering has the highest percentage of professors at $78.05 \%$ in the output range of 1-50; while $13.41 \%$ of professors have no records/publications and output ranges from 51-100 is the highest value for professors of engineering but only with $8.54 \%$. Out of 82 professors in the engineering faculty, $86.59 \%$ have published at least one research paper. With regard to publication output of professors in the faculty of agriculture, the publication range of 151-200 is the topmost but only with $1.32 \%$ of professors; $2.63 \%$ of professors published in the output range of 51-100 and with same $\%$ of professors have no records; about $97 \%$ of professors in agriculture have minimum of one publication.

There are about 139 professors working in the faculty of medicine, with $94.24 \%$ who have published at least one research paper. About $83.45 \%$ of professors have published in the range of $1-50$; nearly $8.63 \%$ have published in the range of 51-100; publication range of 151-200 is the highest value but only with $0.72 \%$ and $5.76 \%$ have no records/ publications as indicated in the table. Faculty of science is the $2^{\text {nd }}$ largest faculty in term of number of professors with the count of 147; about $97.28 \%$ of professors had published at least one research paper; output range from $251-300$ is the greatest value with $0.68 \%$ of professors and about $89.80 \%$ have published in the range of 1 50 , while $2.72 \%$ have not published a single paper. In the case of professors of management and arts, both have published their best in the output range of $1-50$ with $91.31 \%$ and 36.61 respectively. About $63.39 \%$ professors from the faculty of arts have no publications/records and $8.69 \%$ professors from the faculty of management have not published as per the data from the analysis conducted by using Google Scholar.

Table 3 Distribution of Profess ors working in the faculties of Sri Lankan universities on the basis of citation received

\begin{tabular}{lllllll}
\hline Citation & Engineering & Agriculture & Medicine & Science & \multicolumn{2}{l}{ Management } \\
Range values & No. $(\%)$ & No. $(\%)$ & No. $(\%)$ & No. $(\%)$ & No. $(\%)$ & No. $(\%)$ \\
\hline No citation \# & $3(4.22)$ & $5(6.76)$ & $9(6.87)$ & $3(2.09)$ & $9(42.86)$ & $21(31.34)$ \\
$1-500$ & $63(88.73)$ & $65(87.84)$ & $106(80.92)$ & $123(86.02)$ & $12(57.14)$ & $46(68.66)$ \\
$501-1000$ & $3(4.22)$ & $4(5.40)$ & $9(6.88)$ & $13(9.09)$ & $0(0)$ & $0(0)$ \\
$1001-1500$ & $1(1.41)$ & $0(0)$ & $4(3.05)$ & $2(1.40)$ & $0(0)$ & $0(0)$ \\
$1501-2000$ & $0(0)$ & $0(0)$ & $2(1.52)$ & $2(1.40)$ & $0(0)$ & $0(0)$ \\
$2001-2500$ & $0(0)$ & $0(0)$ & $0(0)$ & $0(0)$ & $0(0)$ & $0(0)$ \\
$2501-3000$ & $1(1.41)$ & $0(0)$ & $1(0.76)$ & $0(0)$ & $0(0)$ & $0(0)$ \\
Total & $71(100)$ & $74(100)$ & $131(100 \%)$ & $143(100 \%)$ & $21(100 \%)$ & $67(100 \%)$ \\
\hline Note. \# Includes Profes sors have no citation for their publication. (For more detail see table 2)
\end{tabular}




\section{Citation- based analysis}

The second indicator is the total number of citations. Citation based analysis of professors working in the various faculties, which are presented in Table 3.The use of citation counts are a form of giving credit to recognizing the impact of the authors' work (Cole \& Cole, 1967, 1968). It has been applied to assess the performance of discipline. All professors that had not published any research paper nor have no records were excluded in this analysis. As can be seen in the last row of table 3 , the citation analysis was conducted for the remaining professors who had published at least one research paper based on the data collected from Google Scholar using Publish or Perish software. It is observed that for engineering about $95.78 \%$ of the professors have received at least one citation, while $4.22 \%$ are uncited. Citation range from $2501-3000$ is the highest value for engineering corresponding with the $1.41 \%$ of professors, while about $88.73 \%$ of professors received citations in the range of $1-500$. In the faculty of agriculture about $93.24 \%$ of professors have received minimum of one citation for their output; and only $6.76 \%$ were uncited. In the case of the faculty of medicine about $93.13 \%$ of professors have received at least one citation; majority of professors $(80.92 \%)$ are cited in the citation rage of 1500 ; the citation range of $2501-3000$ is the highest value for $0.76 \%$ of professors. There are about $97.91 \%$ of professors in science have minimum one citations for their credit, while only $2.09 \%$ are uncited. On the other hand, among all six faculties, cited number of professors in management and arts are comparatively low; only about $57.14 \%$ have been cited in management and about $68.66 \%$ of professors in arts have been received at least one citation for their publication; compared to other faculties, uncited professors are particularly high in these two faculties with $42.86 \%$ and $31.34 \%$ respectively.

\section{H-index - based analysis}

Final indicator and metric of this study is the h-index. As discussed by Choi, Holliday, and Jagsi et al. (2013) h-index has become a widely utilized measure of quantifying an individual's research output. In this study, we used the hindex as one measure of professors' performance. All professors that had not received any citations were excluded in the h-index analysis as listed in the first row of table 3 . The h- index analysis was conducted only for professors who had received at least one citation. Table 4 lists the h-index of professors 
in different range values for each faculty; the $\mathrm{h}$ - index range values vary from a high of 26-30 to a low of 1-5 in this table. As for all faculties, Medicine has the highest range value (26-30) of h-index with $0.82 \%$. Majority of professors in all six faculties have h-index in the range value from $1-5$, which is in engineering about $77.94 \%$, agriculture about $82.61 \%$, medicine $56.56 \%$, science $60 \%$, management $75 \%$ and arts about $91.30 \%$ of professors. It is obvious that the performance of professors in arts is comparatively low followed by management; medicine and science are showing a higher; engineering and agriculture are similar in terms of h-index.

\begin{tabular}{|c|c|c|c|c|c|c|}
\hline h-index & Engineering & Agriculture & Medicine & Science & Management & Arts \\
\hline Range values & No. $(\%)$ & & No. (\%) & & No. (\%) & \\
\hline $1-5$ & $53(77.94)$ & $57(82.61)$ & $69(56.56)$ & $84(60.00)$ & $9(75)$ & $42(91.30)$ \\
\hline $6-10$ & $12(17.65)$ & $7(10.14)$ & $41(33.60)$ & $33(23.57)$ & $3(25)$ & $4(8.70)$ \\
\hline $11-15$ & $2(2.94)$ & $4(5.80)$ & $8(6.56)$ & $18(12.86)$ & $0(0)$ & $0(0)$ \\
\hline $16-20$ & $0(0)$ & $1(1.45)$ & $3(2.46)$ & $5(3.57)$ & $0(0)$ & $0(0)$ \\
\hline $21-25$ & $1(1.47)$ & $O(0)$ & $0(0)$ & $0(0)$ & $0(0)$ & $0(0)$ \\
\hline $26-30$ & $0(0)$ & $O(0)$ & $1(0.82)$ & $0(0)$ & $0(0)$ & $0(0)$ \\
\hline Total & $68(100 \%)$ & $69(100 \%)$ & $122(100 \%)$ & $140(100 \%)$ & $12(100 \%)$ & $46(100 \%)$ \\
\hline
\end{tabular}

\section{Overall research impacts of faculties}

It must be mentioned that the overall research performance of professors in their respective faculties. In order to explain the overall performance of faculties we used the mean h-index as measure. The h-index combines the total publications and total citations of an individual author. So, mean h-index was used to measure overall impact of faculties. For this purpose, we included all professors who were working in the faculties as listed in the last column of table 5; the mean h-index calculated for all faculties individually based on all the values of h-index ranged from $0-30$. In addition to the mean h-index, we mapped some other metrics extracted from table 2-4 as summary of this study. As a result, the overall research impacts of faculties are shown in table 5. It seems that based on the mean h-index used in this study, faculty of science is the best performer with the mean h-index of 5.55, followed by medicine (5.24), engineering (3.81), agriculture (3.76), management (2.74) and arts (2.62). Further, as indicated in table 5, faculty of agriculture that has the highest percentage $(97.37 \%$.) of professors, they have at least one research paper; Likewise, faculty of science recoded for professors, they received at least one citation (95.24\%). Faculty of arts has shown the lowest publication 
as well as citation. This must be explained that why faculty of arts and management were showed poor performance.

\begin{tabular}{lllllll}
\multicolumn{7}{c}{ Table 5 Summary of research impact for faculties in the Sri Lankan universities } \\
\hline Faculty & $\begin{array}{l}\text { Mean - } \\
\text { h-index }\end{array}$ & $\begin{array}{l}\text { At least one } \\
\text { publication }\end{array}$ & No publication & $\begin{array}{l}\text { At least one } \\
\text { citation }\end{array}$ & Uncited & Total \\
\hline Engineering & 3.81 & $86.59 \%$ & $13.41 \%$ & $82.93 \%$ & $17.07 \%$ & 82 \\
Agriculture & 3.76 & $97.37 \%$ & $2.63 \%$ & $90.79 \%$ & $9.21 \%$ & 76 \\
Medicine & 5.24 & $94.24 \%$ & $5.76 \%$ & $87.77 \%$ & $12.23 \%$ & 139 \\
Science & 5.55 & $97.28 \%$ & $2.72 \%$ & $95.24 \%$ & $4.76 \%$ & 147 \\
Management & 2.74 & $91.31 \%$ & $8.69 \%$ & $52.18 \%$ & $47.82 \%$ & 23 \\
Arts & 2.62 & $36.61 \%$ & $63.39 \%$ & $25.14 \%$ & $74.86 \%$ & 183 \\
\hline
\end{tabular}

\section{Universities' position in each faculty}

The comparison of universities based on professors' performance, can lead to erroneous conclusion; because some universities in Sri Lanka focus entirely on one field (Eg.University of the Visual and Performing Arts, University of Moratuwa); Further, as noted by Raghuraman et al. (2010), the number of publication and citation/h-index is dependent on the fields and sub-fields. So, we measured universities' position in each faculty individually in order to recognize the best performing university for each discipline on the basis of the mean h-index. As presented in the table 6, the mean h-index of all universities for each faculty was determined based on the professors' performance in their respective faculty and university. These visual representations allow one to easily determine the best university in each faculty in terms of the mean hindex. It was found that University of Peradeniya toped in science with a mean h-index of 7.14, agriculture with a mean h-index of 4.27 , engineering mean hindex of 4.74 and arts with a mean h-index of 3.07. The results showed that out of six faculties, which are grouped in this study, the professors of University of Peradeniya are found to be the most predominant in four faculties on the basis of the mean h-index. Among the faculties of Medicine University of Kelaniya is the best on the basis of the mean h-index with 6.85 . In the case of the faculty of management, University of Jaffna had the highest mean h-index of 7.75. On the other hand table indicates that the performance of arts among almost all of the universities except CBO and PDN were very poor and similar. It should be noted that caution should be exercised while comparing the performance of professors in the faculty of arts allied fields. 
Table 6 Performance of Sri Lankan universities on the basis of the mean h-index by faculties

\begin{tabular}{|c|c|c|c|c|c|c|}
\hline University & Science & Medicine & Agriculture & Engineering & Management & Arts \\
\hline $\mathrm{CBO}$ & 5.97 & 5.59 & - & - & 2.5 & 2.73 \\
\hline PDN & 7.14 & 5.11 & 4.27 & 4.74 & - & 3.07 \\
\hline SJP & 3.68 & 3.82 & - & - & 3.42 & 2.5 \\
\hline KLN & 5.81 & 6.85 & - & - & 2.5 & 2.5 \\
\hline MRT & - & - & - & 3.66 & - & - \\
\hline UJA & 4.65 & 5.25 & 2.5 & - & 7.75 & 2.5 \\
\hline RUH & 5.62 & 4.33 & 3.11 & - & 2.5 & 2.5 \\
\hline OUSL & 4.25 & - & - & 2.5 & - & 2.5 \\
\hline EUSL & 2.5 & - & 2.5 & - & - & 2.5 \\
\hline RUSL & - & 5.25 & 2.5 & - & - & 2.5 \\
\hline SUSL & 6.62 & - & 2.5 & - & - & 2.5 \\
\hline WUSL & - & - & 3.42 & - & - & - \\
\hline VPA & - & - & - & - & - & 2.5 \\
\hline
\end{tabular}

Note. (-) Indicates that no professors/ faculties in the universities. Abbreviations as in Table - 1

\section{Discussion and Policy Implications}

It is assumed that the details presented on the research output of professors working in various faculties of Sri Lankan universities based on the data from Google Scholar, as measured by the currently accepted yardsticks, as credible subject to the limitations identified earlier in the paper.

It seems that in relative terms faculty of science and medicine are the strongest in research output among the six faculties in the university system of Sri Lanka followed by engineering agriculture and management. This observation would confirm the fact that in general terms University of Peradeniya is the most research productive university among these fifteen universities of Sri Lanka; it has the most prolific professors, showing a considerably higher performance in R\&D activities than other universities. We further found that age of the universities and faculties played an important role in their R\&D activities. Professors in the faculty of arts have shown the lowest publication as well as citation. This must be explained that why faculty of arts was showed poor performance in terms of said indicators in this study.

In the promotion scheme for academics in Sri Lankan universities, there is no restriction that academics should publish research articles in refereed/peer reviewed/high impact journals but several marks are allocated for an article published in these journals. On the other hand there is a room for academics 
to attain the minimum score for publications required for the promotion by publishing number books with ISBN, which is an easy way to achieve the required score in Sri Lanka. Majority of University academics in the faculty of arts and social sciences look for publishing books instead of publishing article in high impact/peer reviewed journals for their promotion. In fact, this is one of the important reasons for reflecting the low productivity among the professors in the faculty of arts and social sciences; further, lack of interest in publishing research article in journals is a fact; attitude towards publishing books and books chapters are also common practice among them. High productivity for professors in medicine, science, engineering and agriculture is partly caused by its "English -language" advantage. As noted by Nederhof (2006) that the lack of coverage in the non-English journal online can particularly be considered as a problem for the evaluation of research performance in the social sciences and humanities. This is another reason that local language journals are more common platform for the research communication of academics in arts and social sciences, but they were not covered and indexed in Google Scholar and other citation databases. Further, study found that professors in arts and social sciences certainly received much lower on citation per paper than on paper published. However, this does not means that professors in arts and social sciences are less performers. It is recommended that research output on arts, social sciences and management across the university faculties must be strengthened and mechanism should be introduced by the authorities in order to promote research in arts, social sciences and management.

There are mechanisms in Sri Lanka to promote R\&D activities by the Sri Lankan government. The Presidential Award for outstanding researchers based on the data from Science Citation Index (SCI) is an opportunity to promote and evaluate researchers in the national level. This award system restricted to hard sciences is not suited to management, social sciences, humanities and arts related disciplines. Some professors have written a significant number of publications that are not cited at all or received average citation per paper below 0.5 . In this relation, there was a question that is there any particular factors influencing in receiving citation/h-index for publications of professors? One answer might be that Professors where did their PhD. in terms of country and institute. However this question deserves further study. 
Encouraging development of academics in universities who are both efficient and excellent in research is seen as a necessity for creating a sustainable and healthy research environment. Newly introduced incentives system for academics, new circulars for promotion of professors and other special attempts made by the government of Sri Lanka can be expected to yield a vibrant research culture in the future.

No special attention in Sri Lankan universities is given to academics with relevant research outputs. Existing mechanism to evaluate and encourage the research output in the university system of Sri Lanka is not sufficient to match with international standards. Incentives must be put in place to enables professors/academics under two categories; first category of academics for incentives under active researchers based on their number of publication in high impact journals; second category of academics under impactful/influential researchers on the basis of citation received/h-index.

Further study on the comparative analysis with other databases like Web of Science and Scopus is highly recommended to make the study more meaningful. The study will provide research policymakers with a more complete picture of innovation capability in the research field, and help them to make better decisions. In addition, it will stimulate useful discussions among academics, government and funding agencies about future research direction.

Periodic assessment of university faculties' and departments' research output would motivate the university to move up in its productivity and quality of research contribution nationally and internationally.

\section{References}

Abramo,G., D'Angelo, C.A., \& Pugini,F. (2008). The measurement of Italian universities'research productivity by a nonparametric bibliometric methodology. Scientometrics,76 (2), 225 -244.

Balaram,P. (2008). Scientometrics: A Dismal Science, Current Science, 95(4), 431-432.

Bartneck,C., \& Kokkelmans,S. (2011). Detecting h-index manipulation through self-citation analysis. Scientometrics, 87(1), 85-98.

Choi, M., Holliday, E.B., \& Jagsi, R. et al. (2014) Citation-based Estimation of Scholarly Activity Among Domestic Academic Radiation 
Oncologists: Five-Year Update. Journal of Radiation Oncology, 13(1), $115-122$.

Cole,S., \& Cole, J.R. (1967). Scientific output and recognition. American Sociological Review, 32, 377-390.

Cole,S., \& Cole, J.R. (1968). Visibility and the structural bases of awareness of scientific research. American Sociological Review, 33, 397-413.

Colliander, C., \& Ahlgren, P. (2011). The effects and their stability of field normalization baseline on relative performance with respect to citation impact: A case study of 20 natural science departments. Journal of Informetrics, 5, 101-113.

Etzkowitz, H. (2003). Innovation in innovation the Triple Helix of university - industry - government relations. Social Science Information, 42(3), $293-337$.

Fakhree, M., \& Jouyban, A. (2011). Scientometric analysis of the major Iranian medical universities. Scientometrics, 87 (1), 205-220.

García-Pérez, M.A.(2011). Strange attractors in the Web of Science database. Journal of Informetrics, 5 (1), 214-218.

Guan, J., \& Gao, X. (2008). Comparison and evaluation of Chinese research performance in the field of bioinformatics. Scientometrics, 75 (2), 357379.

Gupta, B., Munshi, U., \& Mishra, P. (2002). S\&T collaboration of India with other South Asian countries. Current Science, 83(10), 1201-1209.

Gupta, B. (2012). Sri Lanka S \&T output during 2001- 2010: A scientometric assessment. Malaysian Journal of Library \& Information Science, 17(3), 49-65.

Harzing, A.W. (2013). A preliminary test of Google Scholar as a source for citation data: a longitudinal study of Nobel prize winners, Scientometrics, 94 (3), 1057 - 1075.

Harzing, A.W. (2014). A longitudinal study of Google Scholar coverage between 2012 and 2013. Scientometrics, 98 (1), 565 - 575.

Harzing, A.W. (2007). Publish or Perish. Retrieved from http://www.harzing.com/pop.htm.

Hirsch, J.E. (2005). An index to quantify an individual's scientific research output. Proceedings of the National Academy of Science USA, 102, $16569-16572$

Ilan, J.B. (2008). Which h-index? - A comparison of WoS, Scopus and Google Scholar. Scientometrics, 74 (2), 257-271.

Imperial, J., \& Navarro, A. (2007). Usefulness of Hirsch's h-index to evaluate scientific research in Spain. Scientometrics, 71(2), 271-282.

Jacsó, P. (2010). Metadata mega mess in Google Scholar, Online Information Review, 34(1), 175 -191. 
Kousha, K., \& Thelwall, M. (2007). Google Scholar Citations and Google Web/URL Citations: A Multi-Discipline Exploratory Analysis. Journal of the American Society for Information Science and Technology, 58(7), 1055-1065.

Mehbuba, D., \& Rousseau, R. (2010). Scientific research in the Indian subcontinent: selected trends and indicators 1973-2007 comparing Bangladesh, Pakistan and Sri Lanka with India, the local giant. Scientometrics, 84 (2), 403-420.

Nederhof, A.J. (2006). Bibliometric monitoring of research performance in the social sciences and humanities: A review. Scientometrics, 66(1), 81-100.

Pethiyagoda, U. (2005). Research productivity in Sri Lanka, Journal of the National Science Foundation of Sri Lanka, 33 (1), 1-2.

Porter, A., \& Chubin, D. (1985). An indicator of cross - disciplinary research. Scientometrics, 8 (3-4),161-176.

Pratheepan, T. (2011). Research Productivity of Sri Lankan Universities during 1999-2010 based on the ISI Web of Science database: a Scientometric study. Proceeding of the University Librarians Association Sri Lanka, 288 - 295.

Raghuraman, K.P., Chander,R., and Madras, G. (2010). Scientometric analysis of some disciplines: Comparison of Indian institutions with other international institutions. Current Science, 99(5), 577-587.

Wickremasinghe, S.I. (2008). Evaluating research productivity: a case study of the rice scientists in India and Sri Lanka. Journal of the National Science Foundation of Sri Lanka, 36 (1), 59-68. 